\title{
A Non-Failing "NeoBlend-Digit" Schooling Free of Conventional Teachers: A Blueprint for a Futuristic Learning Open to Infinity
}

\author{
M. Ziad Hamdan \\ Correspondence: M. Ziad Hamdan, Hamdan Academy for Higher Education Online, Webhosting, Selangor, Malaysia.
}

Received: March 26, 2018

doi:10.11114/ijce.v1i1.3246

\author{
Accepted: April 26, $2018 \quad$ Online Published: April 27, 2018 \\ URL: https://doi.org/10.11114/ijce.v1i1.3246
}

\begin{abstract}
The practice of Blended learning in schooling for almost two decades has shown limited variations from what conventional education had breached hundreds of years ago. In that, continuing the use of large groups teaching, big chunks of required curriculum for learning and instruction, unified mandatory knowledge for all students, the lack of individual achievement pace, unified daily study schedules, and same backward assessment tools and formalities. Yet, ICTs exert every moment profound remote digital penetrating power into the deep privacy of human anatomy, actions, family and daily lives in what could be called the "Age of digital Information Nudity". Moreover, resource teachers or students' counselors are able by a click at a digital curriculum to reveal where learners' locations are, how many times attempted reading, performing assignments, or what study difficulties they are facing. ICTs have dismantled all the psychological, social, educational and physical boundaries separating peoples, businesses and schooling communities. Students living currently in digital environments have a free will through digital means to decide, plan, in addition, to using types, tools, times and settings for their blended and online learnings, even without the pre-consent of school authorities. Hence, a new form of blended education deems crucial, that is "neoBlend-Digit" Schooling. This new hybrid methodology, when well served by developmental appropriate curriculum design, thoughtful treatment of curriculum content, a systemic implementation framework (diagnostic, formative and summative), and optional multi learning tracks, will lead to open ended learning free of failure, outdated teachers and school personnel, and environmental limitations. Consequently civic citizen students are graduating as literates, professional specialists, and academic pioneers.. Realizing as such what the American educator, William Glasser* wished for "Schools without Failure". In current work however, the long waited dream of Glasser is presented in a concise digital language and concretely accountable educational evidences in field reality.
\end{abstract}

Keywords: blended schooling, learning open to infinity, multi learning tracks, multi-stage schooling, "neoBlend-Digit" schooling, schooling free of conventional teachers, spiral curriculum design, student school government

*Glasser, William. 1975. Schools without Failure. Paperback-June 25, 1975. https://www.amazon.com/Schools-Without-Failure-William-Glasser/dp/0060904216

\section{Introduction to "neoBlend-Digit" Schooling}

The most important purpose of schooling in the ICTs' Age should not be learning for storing knowledge per se, rather for using it in real life and work situations Davis,2017; Hamdan, 2017. However, by the beginning of Third Millennium Blended learning (BL) has been developed to a new applied educational science as a mix of concrete conventional and online schooling (Lorenzetti, 2014).

However, developments of digital technologies are ever speedily unfolding, which most likely motivated Eric Schmidt, and Jared Cohen to predict, "Everyone in the world will be online by 2020"(John Naughton.2013).

David Warlick.2016 added "We need technology in every classroom and in every student and teacher's hand, because it is the pen and paper of our time, and it is the lens through which we experience much of our world"(Warlick.2016).

Generally, schooling has experienced by the advent of third Millennium profound changes in its methodology appearing through transforming face-to-face residential schooling into blended and online approaches, where U.S. schools and higher education institutions have the lead in this domain (Hamdan,2015).

However, Floridi $2018^{\mathrm{A}}$ stated that people are no longer living online or offline but "onlife" which represents a special space, or info sphere. This info sphere is analogue and digital, offline and online. The results of these massive contexts 
are overwhelming technology encounters that could lead to anxiety since "onlife" disrupts the normal daily pursuits of the analogue society, e.g. production, logistics, customization, competition, education, work, health, entertainment, politics and security, just examples.

In addition, Floridi. $2018^{\mathrm{B}}$ pointed out that digital ethical problems also have aroused, representing a clear challenge for people living in the 21 st century. These include "breaches of privacy, security and safety, ownership and intellectual property rights, trust, and fundamental human rights, as well as the possibility of exploitation, discrimination, inequality, manipulation, propaganda, populism, racism, violence and hatred speech".

Nazeeri 2018 referred above disappointments to a technical fault commited by school and university, which gives more importance on putting courses online far more on student's welfare. He found in his study that "most institutions tend to anchor their thinking to their existing on-campus courses. This approach is limiting at best and a recipe for mediocrity in many cases. Instead of thinking about your new online initiative-whether it is a single course or an entire degree program - as a generic rework of your on-campus courses, we recommend thinking of it as an entirely new educational experience. A new product. One that demands that you carefully evaluate all your requirements and ensure the program is designed specifically with your target audience of current students and prospective students in mind".

Nazeeri 2018 added that one basic problem hindering the success of schooling reform efforts is also adopting a subjective "patching" technique in reforming traditional education by means of blended and online approaches. The fundamental concern in most cases appears in "How do we put these courses online?" in isolation of needs, characteristics and goals of learners, instructors and school or college environments

Hamdan, $2016^{\text {a }}$ observed that despite some fifteen years have passed on the practice of BL and eLearning in schooling and even though there is an over demand for them as "consumer preference that exceeded reported experiences, not many differences have been noticed from what was mandated by the large groups' Factory Model, which offers students big portions of the required curriculum to be learned at one specific time. BL throughout the past above years has been administered with students using unified content and methodology, supported by few theoretical assignments or activities to be achieved by all students regardless of their academic aptitudes, time availabilities, personalized learning needs, or future purposes of learning: e.g. literacy, professional work or academic distinction.

Davis 2017 supported above observations in a critical article of American schooling and presented five educational reforms to prevent thwarting the progress of American education both face-to-face meetings and online forms during the coming twenty years. These five proposals are briefed in the following points:

1. American education system is unsustainable and ill-suited for a globally connected world that is constantly changing.

2. Colleges and universities will have to change their current business model to continue to thrive, boost revenue, and drive enrollment.

3. Data and the ability to transform that data into actions will be the new lifeblood of the institution.

4. The lecturing and written documentation are not educationally sustainable; new technologies will allow faculty to shift their focus on the application of learning rather than the acquisition of knowledge.

5. the most important for any institution is its people. Hence, adopting new technologies is the basic step for positive change; institutions however, must work with faculty and staff to initiate a fundamental change in the institutional culture.

Dewey and Regenstein 2003 confirmed that introducing ICTs and "Blend-Digit" in schooling necessitate devising plans for changing schools' and higher education's information technology infrastructures that will help creating more effectively functional libraries, campus IT organizations and centers, digital equipment and connected new classrooms; and achieving as well campus-wide IT leadership roles, trends in and strategies for departmental planning, public policy, capital investments, intellectual property, teacher education, reorganization of school and university staff structures, and integration of IT services throughout the "Blend-Digit" environments.

Moreover, while much of the content of "neoBlend-Digit" programs can be delivered through "self-administered" elearning, teachers can concentrate on roles as mentors and collbarators with students in developing the skills of information management, understanding and questioning, critical thinking and knowledge application. Thus, digital media can facilitate more active problem-based learning, which has the merit of encouraging greater student engagement and leads to better learning outcomes. Digital assessment tools on another hand, can enable quick feedback on student progress and curriculum adjustment to student needs (Vassiliou and McAleese 2014).

Vassiliou and McAleese added, several universities in the United States have programmed software to enable teachers to monitor their student's performance live. With the help of massive availability and usability of data as done for example by Stanford's Lytics Lab. the Open-Learning Initiative of the Carnegie Melon University and the Check-My- 
Activity-Tool of the University of Maryland which enable students to monitor their own performance and adapt it according to required results.

ICTs have many implications to education. Cromwel 2015 wrote an article on a new project called "School of the Future". It uses mostly the blended approach, and It is generally community-style center operating seven days a week, 24 hours a day." Computers are essential ingredient for effective operation and education of school of the future. It is surprisingly found that the content of the school of the future is highly comparable to the a work published 1988 in Arabic then in English 1999 by this author (hamdan 1988, 1999).

Moreover, EMMA organization 2014 provided in Europe a system for the delivery of free, open, online courses in multiple languages from different European universities. There are currently many universities and companies in several European countries are participating. Coursera, FUN, FutureLearn, Miríada X, Open Classrooms are example (EMMA, 2016).

The practice of "Blend-Digit" education through MOOCs and technology tools including "internet of things", school communities have freed learning and teaching to infinity and in many cases free of charge. Hence, there is no excuse for any individual, group or community to claim illiteracy of any kind since it is available in huge varieties and quantities online.

Barnes and Noble College study report 2017 notes that the number of non-traditional students is projected to increase more than twice as fast as traditional students from 2012 to 2022, according to the CLASP Center for postsecondary and economic Success. In addition, non-traditional students are among the fastest-growing student groups, this means schools face retention challenges.

The FBOL 2017 reported that the total number of students in the United States attending online and blended schools is estimated between one and two million students, or roughly $2-4 \%$ of all students in the country (though Allen and Seaman 2016 stated a total of 2.8 million students taking all of their higher education which represents one-in-seven (14\%) of all higher education students). Further, more than half of all states allow online schools that draw students across district boundaries; perhaps 350,000 students attend these schools. Other students in this study are attending online schools that serve students within a district or sub-state region, blended charter schools, and alternative education programs.

Online Learning Consortium 2017 conducted a survey for the total university students studying online across the world and found that over six million students are distant learners, more than $50 \%$ of them are American. These figures however seem relatively unrealistic since more talking, experimentation and practices of ICTs are widely observed in reality.

None-the-less, the real problem beyond unease feelings of practitioners towards online schooling lies in the instable status of ICTs field. This due to over consequtive developments, which leave technicians and spcialists coupled with school workers who are lacking the systematic technical training, which leave them unable to comprehend the technological knowledge and skills that help teachers and students in their learning and istruction. What is needed is a new methodology that consolidates digital data utilized in schooling so that all required factors, processes and outcomes of learning and instruction could purposefully channeled towards the achievement of intended curriculum or program.

Therefore, the focus of this article is producing a "neoBlend-Digit" methodology for schooling personnel and learning generations in k-12 to B.Sc in higher education. The methodology is in essense an operattional framework that enables learners and none-directive resource teachers to utilize several techniques of face-to-face encounters, the internet and "e-clouds", micro blended curriculum units, mobile/tablet equipment, and personalized learning in achieving their goals.

The "neoBlend-Digit" methodology is realized through answering eight guestions in the following paragraphs.

\section{Article's Questions}

1- What is the concept of "neoBlend-Digit" Schooling?

2- What are the expected consequences of "neoBlend-Digit" approach on modernization of schooling?

3- What are the construct transactions of "neoBlend-Digit" Schooling?

4- What are the Four Operational factors of "neoBlend-Digit" Schooling?

5- What are the nature and content of Curriculum Design for "neoBlend-Digit" multi-stage Schooling?

6- What are the Methods, techniques and Quality Issues of "neoBlend-Digit" Schooling?

7- What are the possible learning achievement tracks for non-failing "neoBlend-Digit" schooling?

8- How could Futuristic "neoBlend-Digit" Learning be Open to Infinity? 


\section{What Is the Concept of "neoBlend-Digit" Schooling?}

\section{Academic Terms}

Eight major terms are used in the article and are explained as follow.

1- Age of Digital Information Nudity: The huge sophestigated advancements of ICTs enabled digital tools, software and gadgits to infiltrate deeply in the ground for recovering natural resources, to perform A/V recordings by means of setelites and internet lines of any person, sound, movement and action. Hence, self- awareness and management control should be considered to void intruding into one's privacy.

2- Blended schooling: It combines online learning with a physical campus where face-to-face meeting is employed. In most cases, blended schooling provides scheduling flexibility to students, allowing them to learn online in lieu of being on the school campus every day.

Seaman and Allen 2016 offered however a classification of online and off-line learning according to on-ground/online practices. These types appear in Table 1(adapted after, Allen, Seaman and others 2016).

Table 1. Types of schooling according to on-ground/online practices

\begin{tabular}{c|c|c}
\hline $\begin{array}{c}\text { Proportions of } \\
\text { Content Delivered } \\
\text { Online }\end{array}$ & Type of Course & Typical Description \\
\hline $0 \%$ to 20 & $\begin{array}{c}\text { Traditional With Some } \\
\text { Web Facilitions }\end{array}$ & $\begin{array}{c}\text { Course content is delivered orally with sporadic uses of web-based technology } \\
\text { to facilitate what is essentially a face-to-face course. It may use a learning } \\
\text { management system (LMS) or web pages to post the syllabus and assignments }\end{array}$ \\
\hline 21 to $80 \%$ & Blended/Hybrid & $\begin{array}{c}\text { Course that blends online and face-to-face delivery. Substantial proportion of } \\
\text { the content is delivered online, typically uses online discussions, and a reduced } \\
\text { number of face-to-face meetings. }\end{array}$ \\
\hline $81+\%$ & Online & A course where most or all of the content is delivered online. Typically have no \\
face-to-face meetings
\end{tabular}

3- Learning is Open to Infinity: "neoBlend-Digit" approach combines on ground and online schooling means for the service of learning and instruction for some past years. Hence, individual students and peer groups have a total flexibility to determine and plan what they tend to learn at the time and place convenient to them whether being inside or outside their schools and nation states. Thus, individual students and peers are free to learn like the case of breathing oxygen in the air.

4- Multi Learning Tracks: the central philosophy of "neoBlend-Digit" methodology in this article is responding through "personalized learning" to student individual differences in aptitude, attitude and personal academic/ professional choice for the future. The learning options available to students are three: Literates, Specialists, and Pioneers. For details, please refer to a later paragraph.

5- Multi-Stage Schooling: it covers all major educational phases of schooling that generations are psychologically and physically ready to build their intellectual and professional skills, and certification ambitions. These stages encompass specifically nursery and kindergarten, lower elementary, upper elementary, junior high (middle school), senior high (secondary school), BSc, MSc/ MA and PhD studies.

What distinguishes the current research topic as indicated above is the spiral continuity design of its content in that each schooling stage from nursery up to $\mathrm{PhD}$ studies has a continuum interrelationships. Each consecutive stage offers students goals, knowledge, values, skills, learning and achievements that are highly and inductively related. Actually, schooling stages are similar to the ring chain in their curricular, learning, and teaching connections. All are meaningfully inter-connected with previous and next grades, stages.

This author strongly believes that a cardinal reason beyond the failure of education systems is their negligence of promoting the principles of inter-dependence and continuity between schooling curricula or courses and learningteaching strategies used in consecutive grades and stages. Needless to emphasize that these curricular and pedagogic principles provide schooling with meaningful preconditions of applicability, validity and reliability necessary for effective students' leanings.

6-"neoBlend-Digit" Schooling: It is different and more advanced methodology of schooling than any educational practice before. It combines simultaneously blended and online techniques and lead when scientifically applied to learning free of the "factory Model" teachers and as well to learning choices open to infinity in curriculum options, learning tools, techniques, facilities, and time in and out of learning sessions. "neoBlend-Digit" schooling gives students total and open freedom to decide and initiate their individual and peer groups' learnings. 
"neoBlend-Digit"schooling is academically criterion-referenced learning, achievement, and assessment (never normreferenced, which doesn't guarantee quality outcomes). It is responsive to individual student, peer groups and as well to the needs of education market place. its learning is based on educational/ clinical prescriptions that respond to learners' self-paced; individual and small groups' learning initiatives; and for self and peers' formative learning reviews, and it supplies students with alternative education sources whenever are needed (FBOL,2017).

The (FBOL, 2017) was established to advance and improve the availability and quality of blended and online educational opportunities for students and teachers and to strengthen the outcomes of schooling programs through active academic, instructional, and technology integration for personalized learning. Thus representing the crux, goals and principles of "neoBlend-Digit" Schooling.

Rose, 2016 explains that many institutions, including schools, base their activities on their expectations of what an "average" person is, and assume that each individual person is similar to the average. In fact, this assumption is often misleading. In psychology, there is no such approved valid and reiable concept in schooling.

For example, students who get B grade while are differing in several individual characteristics, life conditions, and family backgrounds such as socioeconomic status, culture, aptitude, health condition, personal developmental ambition and hobbies, can't be treated in lieu of the "average"student or person since the content, the brain and physical internal processes, and implications of results for the future are non-identical among B students. This creed of "end of average" is exactly similar to the belief and principles, which"neoBlend-Digit"methodology advocates and operates accordingly.

While much of the content of "neoBlend-Digit" programs can be delivered through "self-administered" elearning, teachers can concentrate on their role as mentors, developing with students the skills of information management, understanding and questioning, critical thinking and knowledge application. Thus, digital media can facilitate more active problem-based learning, which has been demonstrated to encourage greater student engagement and leads to better learning outcomes (Vassiliou and McAleese, 2014). Digital assessment tools can enable quick feedback on student progress and curriculum adjustment to student' neeeds (Hamdan, $2016^{\mathrm{c}}$ ).

7- Online schooling: Provides students' entire education via the Internet, with very little or no in-person contact between teachers and students. Digital instructional materials are delivered online and physical instructional materials by means of email, digital phone, video chats, text chats, discussion boards, and other online techniques.

Students are full-time online as required by the education system. They are not obliged to visit the traditional campus, nor does the school offer a physical location for students. Instead, a student's entire education is built around interacting with teachers and peers using online communications, as well working with both online and digital instructional materials ( FBOL, 2017).

However, online schooling despite rising heavily in practice worldwide is expected to never be the sole approach for schooling due to different nature of individuals in growth needs, cognitive and psychosocial modalities, and availability of enviromental responsive sources. There will be environments that are high, fair or low in applying e-learning, but will never reach $100 \%$ or $0 \%$ points practice in schooling reality (Hamdan, 2017).

8- Schooling Free of Conventional Teachers: the wide spread practice of ICTs in education, and the current proposed launching of "neoBlend-Digit" learning in schooling, have made it possible to negate the roles of "corporal and large groups teachers". Their roles in implementing the "neoBlend-Digit" methodology with students should be inactivated until they affirm their ICTs professional knowledge and skills. Brief qualifications and job descriptions of these new teachers are presented in paragraph four.

9- Spiral Curriculum Design: Spiral curriculum design (Harden and Stamper,1999; Johnston, 2012) is composed academically of serial connected loops, each represents a course, a topic or a subject within a learning sequence leading at the end to achievement of a class grade, a stage, or a BSc., Master's or PhD. Degrees as the case of higher education (figure 1 and 2). 

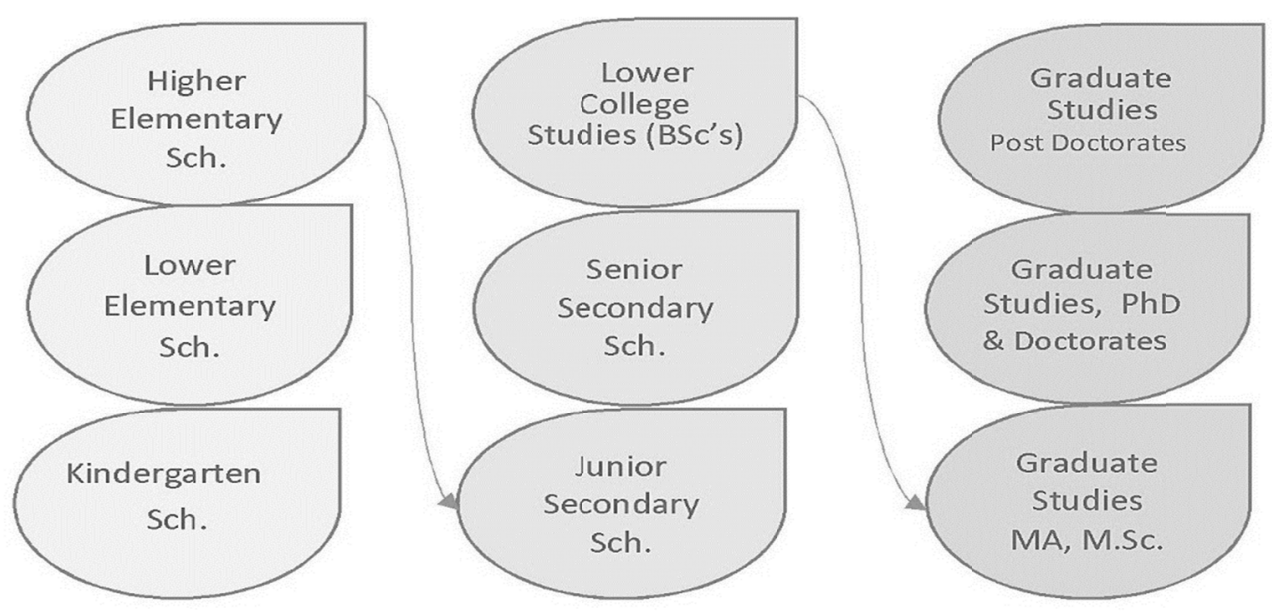

Figure 1. A Developmental Spiral Curriculum Design for Multi Stage blended schooling

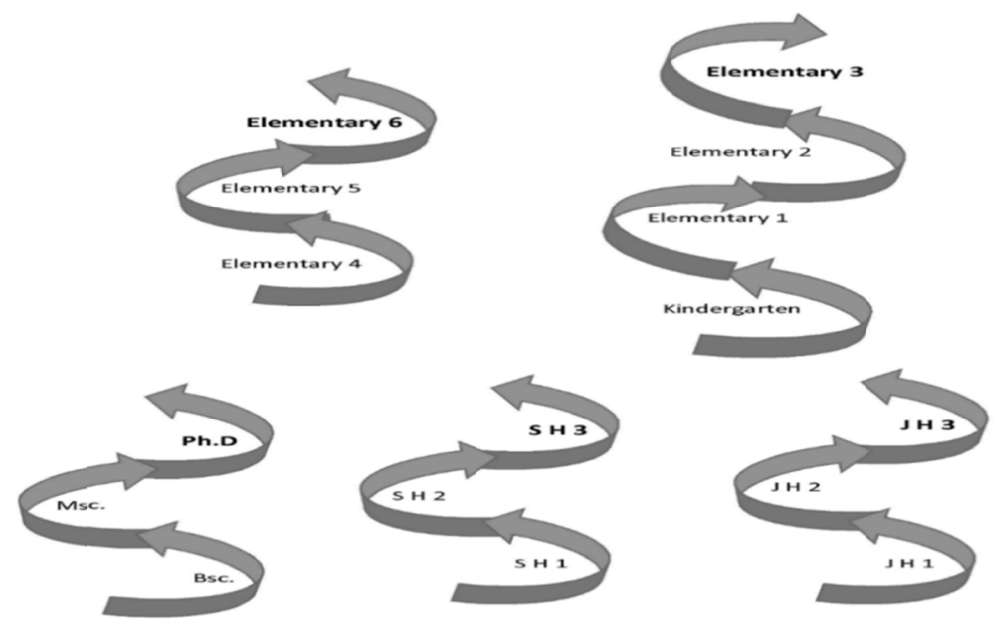

Figure 2. Alternative Diagram of the Developmental Spiral Curriculum Design for Multi Stage blended schooling

10-.Student School government (SSG): It is a training managerial framework representative of the political government in reality. While students collaborate with school administration in self-management of learning, implementing curricular, teaching, organizational, recreational and maintenance tasks.. students governments could be: kindergarten children government, lower elementary pupils government, upper elementary government, junior high (middle school), senior high (secondary school), and B.Sc.'s academic years governments.

These governments presume functions as: peers delegators, none directive peer counselors, peers torturing coordinators, peers assessment advisors, and peer group leaders who assume the management of daily maintainance tasks . This socio-political concept is in fact a training procedure and a framework for developing good citizenswho are equipped through civic schooling with knowledge, values and skills of democracy, tolerance and human rights(Hamdan, 2018. February 9).

What are the expected consequences of "neoBlend-Digit" approach on modernization of schooling? Optimal effects of "neoBlend-Digit" approach on Modernization of schooling

When applying "neoBlend-Digit" approach to schooling, the following positive consequences are most likely observed (Hamdan, RE-SCHOOLING SOCIETY 2016): 
- Transforming school buildings into connected variant up to date facilities where simple conventional classrooms equipped basically with students' desks and a black or whiteboards are replaced by connected counseling classrooms or clinics (figure 3) for social studies, native language, foreign language, math, science, fine arts, home economics, computer science, slow learners, behavioral modification, exceptional students, learning enrichment, Vocational skills. In addition to new equipment and facilities for study carrels, special tutoring, small groups discussions, test finals halls, achievement reports office.

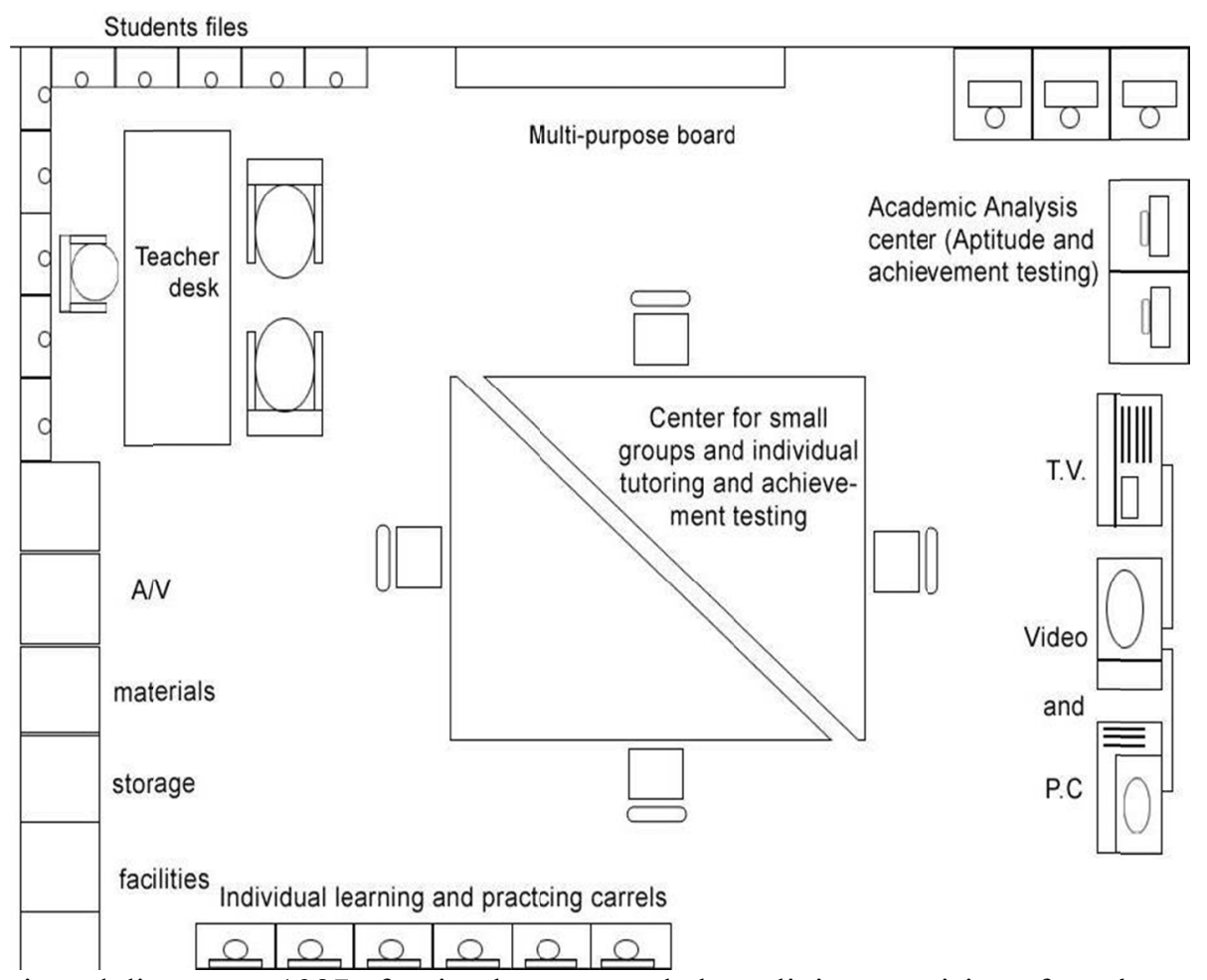

Figure 4. A projected diagram at 1987 of a simple connected class clinic comprising of one large room(Hamdan, $2016^{\mathrm{b}}$ )

- Building school society where students have become the center of learning Universe who presume the responsibilities of managing, controlling and maintaining the quality of "neoBlend-Digit" schooling.

- Building mutual interactions, understandings, and collaborations among school communities and educational systems across the World for more effective education.

- Building inter-independent civic school populations on state, regional and global levels as they interact daily with a sense of purpose, personal dignity, mutual understanding and respect.

- Producing successful generations who are according to their special aptitudes and hobbies are able to be literates, professionals and superiors in school subjects based on the "trio study tracks" of non-failing "neoBlend-Digit" Schooling.

- Freeing schools and school communities based on the qualities of "neoBlend-Digit" instructors, students and school personnel from job failure and the need for conventional schooling staff.

- Building World peace, mutual appreciation, and tolerance on local, national, regional and global levels as they are able through ICTs and digital school and global societies to communicate, interact, and perform peer groups collaborative learning and mutual friendships.

\section{Exploring the Developmental Spiral Curriculum Design for non-failing "neoBlend-Digit” Schooling}

\section{1- Bases of the Developmental Spiral Curriculum Design (DSCD) for "neoBlend-Digit" Schooling}

In pedagogical language, the term "neoBlend-Digit" design encompasses national/cultural characteristics and elements; blended teachers and students; blended and digital curricula; technological factors and means, ICTs based equipment and methods; and quality "neoBlend-Digit" schooling facilities, which all together determine the gestalt identity of "neoBlend-Digit" learning and instruction. Any weakness or missing element of these foundations will reflect negatively upon the validity and effectiveness of the blended and e-schooling design. Brief details follow. 


\subsection{National/Cultural Characteristics and Elements Base of DSCD}

The content of this design base represents the local "genetics" composed of geopolitical, educational and cultural priorities that distinguish the individual local nation among World states and considered at the same time societal distinctive merits among Global communities. It could be indicated here that while national "genetics" of "neoBlendDigit" schooling keep the local identity intact, the ICTs enable native school systems to succeed in transforming educational priorities and practices into concrete actions on ground and nation schools into transnational regional and global interactive institutions.

\subsection{ICTs Base of the Developmental Curriculum Design}

This base represents the operating hardware genetics of schooling and contains all technological factors, tools/equipment, and methods that are necessary for the operation of "neoBlend-Digit" schooling in reality.

The ICTs base could utilize all fundamental electronic factors, common to all educational environments worldwide such as digital equipment (e.g. the Internet), tools (e.g. desktops, laptops, tablets and mobiles), general operating rules and instructions, hosting "neoBlend-Digit" facilities (e.g. connected classrooms, information centers, study booths or carrels, collaborative resource rooms, and the "neoBlend-Digit" libraries).

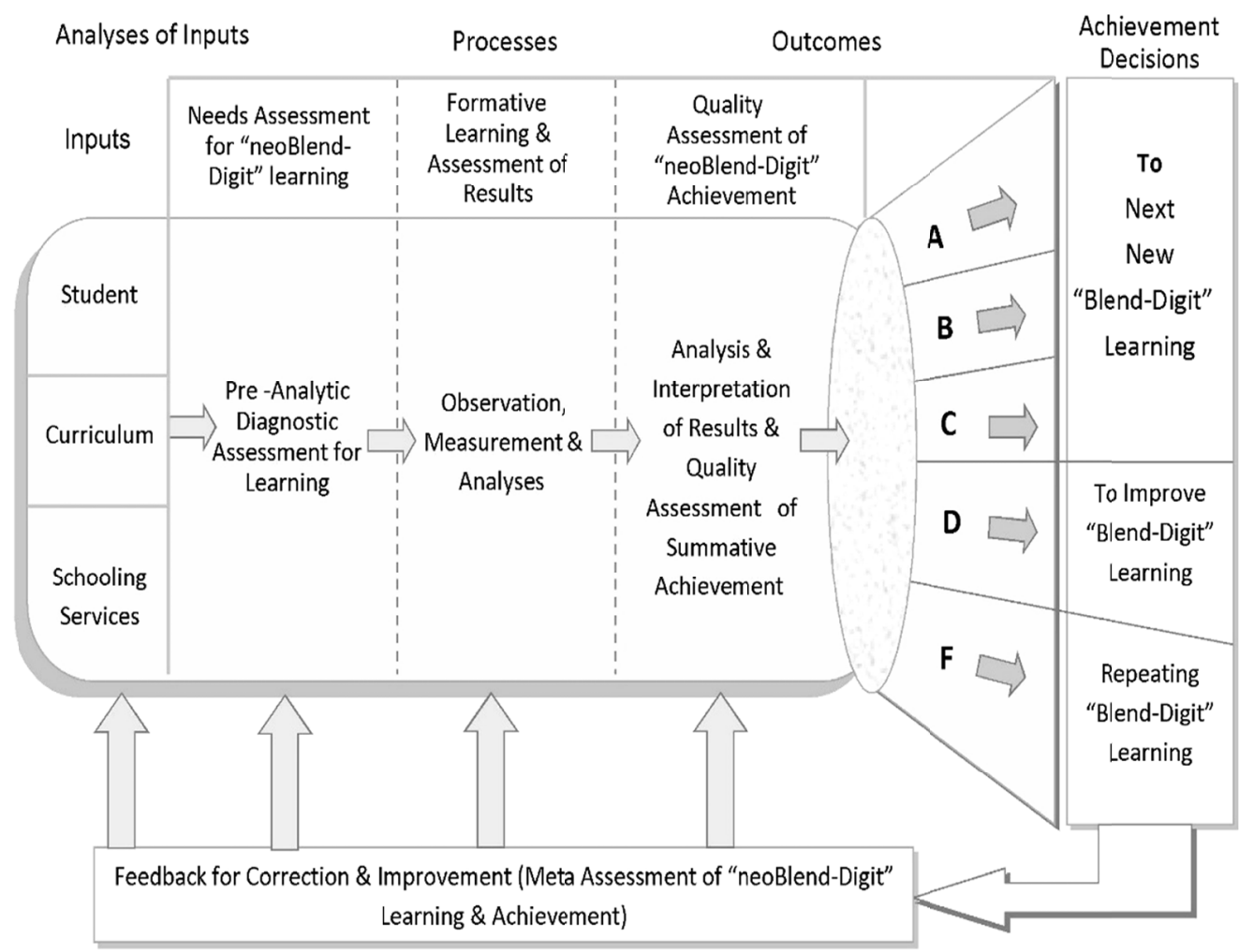

Figure 5. A Systemic Framework for neoBlended Learning and Assessment of Achievement

\section{What Are the Construct Transactions of "neoBlend-Digit" Schooling?}

\section{Three Construct Transactions of "neoBlend-Digit" Schooling (nBDS)}

The major transactional operations that constitute "nBDS", are: schooling preparation of inputs, which focus on analyses, and diagnosing of students' backgrounds and needs, school personnel and services involved in accomplishing "nBDS".

Specifically, these transactional tasks" are: analyzing of "nBDS" inputs, Formative "neoBlend-Digit" Learning and instruction, and Summative evaluation of "neoBlend-Digit" Learning results. Brief illustrations follow (Hamdan, 2015).

\section{1 "neoBlend-Digit" Schooling Inputs}

The entering data of "nBDS" could be specified through the following tasks: Analyses and diagnoses of pre-learning knowledge of required course(s), e-Learning needs, e-Instructional givens (academic knowledge, blended counseling and guidance skills, blended teaching and learning techniques/methods, and blended educational assessment and evaluation) are reviewed and specified, coupled with previous elements, which are already operating. 
The main mandatory inputs that should be studied at this stage of "neoBlend-Digit" schooling are (Figure 4):

The working components of "neoBlend-Digit" schooling are organized in three conventional categories composing any educational system: inputs, processes and outputs (Figure 4).

Students who are seen in lieu of the Global Digital Age and Learner-Centered Paradigm, self-learners of all ages.

The "neoBlend-Digit" curricula. They are simply the academic messages of blended and online learnings, which determine the types, and contents of achievements.

"neoBlend-Digit" schooling services. They are briefly of the following categories:

- Human Services, e.g.: Resource teachers, Educational aides, Psychologists, Student Counselors, Technicians, Assessment personnel, Maintenance Services, Managing Services and Financial staff.

Needless to indicate that the roles of schooling human services should transform to "neoBlend-Digit" coordinators, assistants, counselors, technical aides and educational clinicians.

- “neoBlend-Digit” Schooling Facilities, e.g.: Connected classrooms, computer stations, tutorial center or areas, study carrels, learning clinics or learning diagnosing laboratory, seminar and discussion classrooms, learning resource center or resource rooms and blended library.

- “neoBlend-Digit” Schooling Equipment, e.g.: Internet lines, Laptops, mobiles, Tablets, school audio and video circuits, and other possible types of machinery, devices, and tools.

\subsection{Formative "neoBlend-Digit" Learning and Instruction Prescriptions}

This is the building stage of required achievement where blended clinical learning-instructional documents prescribe for each student the objectives, knowledge content, plans and assignments, specifications of achievement results; human, technical, and physical support services that each student should encounter throughout formative "neoBlend-Digit" implementation. The achievement outcomes of this phase enter the summative assessments for reviews and evaluation of qualities.

\subsection{Summative Assessments and Policies of "neoBlend-Digit" Learning}

Examining "neoBlend-Digit" learning results at this final phase of schooling through appropriate quality measures and against specified summative standards.

it is critical to the success of "neoBlend-Digit" schooling to redesign learning assessments and policies to fit the demands of students' growth and achievement needs. It is proposed here, besides the limited use of summative evaluation at the end of each studied course, to adopt the two previous types of assessment: pre-learning diagnostic and during learning formative assessments.

Diagnostic assessment concerns itself with specifying where each student had already achieved of the required knowledge and skills before learning, specifying thus what he or she should learn. When comparing pre-learned knowledge of each course with achieved results, he or she can specify the quality degree of achievement (Hamdan,14)

\section{What Are the Four Operationing Factors of "neoBlend-Digit" Schooling?}

\section{Four Operational factors of "neoBlend-Digit" Schooling}

While much of the content of "neoBlend-Digit" programs can be delivered through "self-administered" elearning, teachers can concentrate on their role as mentors and collaborators with students in developing the skills of information management, understanding and questioning new knowledge, critical thinking and applications. Thus, encouraging greater student engagement that will lead to better learning outcomes (Hamdan, 2016 ${ }^{\mathrm{a}}$ )

The four factors basic to the operation of "neoBlend-Digit" Schooling, are: "neoBlend-Digit" teacher, students, the curriculum, and counseling resource room/ hall and the educational connected clinic. Brief illustrations follow:

\subsection{The "neoBlend-Digit" Education Teacher}

The "neoBlend-Digit" education teacher is a professional consultant, a diagnostician, a behavioral researcher, a prescriptive educator, a none-directive counselor and a responsive evaluator. He assumes these roles as matters of principles similar to those carried out by the physician in medical clinics.

\section{The "neoBlend-Digit" teacher is a professional who is:}

- Consultant as an expert educator confers with students, listens to their psychoeducational needs, shares with them views and feelings, differentiates among probable treatment alternatives, and advises in selecting final solutions. 
- Diagnostician as he conducts interviews, administers educational/behavioral tests and questionnaires, gathers and organizes data, analyzes personal backgrounds, correlates factors with observed needs, and finally identifies the nature of needs, difficulties or problems at hand.

- Behavioral researcher as he investigates students' behaviors to make generalizations concerning its validity and productivity for life/society and schooling.

As the qualified researcher does, the clinical teacher observes educational and behavioral needs, gathers and organizes data, analyzes and interprets causes and effects and formulates conclusions regarding the best ways by which new learnings or modifications of conduct could be achieved.

- Prescriptive educator. The clinical teacher usually gathers information concerning students' educational and behavioral needs, as the physician does. As such, he has the basic data on which could build appropriate prescriptions with collaboration of students to satisfy their stated needs.

These written prescriptions may include new learnings or mandated behavioral modifications. Hence, prescriptions in order to meaningfully implemented by students and teachers should specify the professional personnel, the curricular materials, study units or subjects, digital media and technologies, the equipment and facilities; and the achievement schedule through which individual students could successfully pursue their developmental or corrective tasks.

- None - directive counselor. The role of the clinical teacher here is parallel in nature to that of the physician in medical care. He/ she thus listens carefully to students while are talking about their needs, discusses with them possible causes and effects, and advises for useful treatments. Then the counselor teacher monitors with collaboration of students the implementation of prescriptions, assesses results and provides students with necessary achievement feedback.

- Responsive evaluator: The "neoBlend-Digit" teacher as responsive evaluator focuses on the quality of learning activities and experiences, responds to students' needs for new learnings or for behavioral rediscoveries by means of modification / correction, and works with the principle of individual differences among students in regard to abilities, desires / attitudes and aspirations. The clinical teacher as a responsive evaluator seeks throughout the course of judging tasks, the collaboration of other professionals such as the school psychologist, the educational psychologist, the physician, the medical analyst, and more if needed.

The "neoBlend-Digit" teacher in doing above gathers students' data from several sources, checks its validity to students' cases, provides students with proper feedbacks concerning their current educational and behavioral statuses and the actions, which they could be adopted to overcome the observed inadequacies. Treatment reports on implementation of prescriptions are finally written and distributed to individual students.

\subsection{The "neoBlend-Digit" Student}

The "neoBlend-Digit" learning Student is a self - motivated initiator and a committed individual, who takes decisions, carries them out and holds him/ herself responsible for the results. In "neoBlend-Digit" schooling, there must be a student who:

- feels her/ his needs,

- has the desire and will to fulfill them by appropriate psycho-educational means,

- decides to visit the educational clinic,

- consult a clinical teacher,

- have learning prescriptions,

- implements fully treatments,

- evaluates results and

- Selects from alternatives / directions a step, which advances her/ his achievement.

In reality, without above students' qualities and tasks, "neoBlend-Digit" schooling, as well as the traditional one, can never be successful. Actually, a great deal of our failure in education stems from the compulsory management measures, the strict administrative procedures and techniques, and from the overall unspoken philosophy of schooling of "education of the masses"...never the individual, despite the desperate propaganda which is unconvincingly launching by most parties, especially in the underdeveloped and Developing countries.

For schooling to be productive, the student must initiate decisions and actions, and never let others initiate schooling for her/him. As the student chooses enthusiastically for example to attend a concert or a play, to go camping, to socialize for hours, he/she could with the same moving instinct consider schooling a daily priority and a tool for achieving higher developmental goals. 
One procedure, which may encourage a student to rise from being a receiver of education to an initiator and active decision maker, is to transform schooling from its large groups theoretical lecturing, compulsory unified and corporal approaches, to a diagnostic, individualistic and highly responsive to student's engaging by means of ICTs in personalized learning of academic curriculum content. Dewey, William James and the Progressive Movement brought about and practiced this philosophy of active schooling founded at early eighteenth century 'Smart, 2007; Hayes,2006)

The Contemporary Small-School Movement of the 1960s is live example of two hundred years extended influence of Dewey, James and the Progressive-Education Movement (Semel and Sadovnik, 2008) .' In addition, the present "neoBlend-Digit" progressive approach to schooling is an advanced alternative based heavily on the utilization of ICTs, globalization, and the principles of Humanistic, Gestalt, and Pragmatic psychologies.

\subsection{The "neoBlend-Digit" e-Curriculum}

It is simply the academic message of "neoblend-digit" learnings that determines types and contents of students' achievement. Hence, the basic concern of this fundamental educational document is to be valid and reliable for students' characteristics, goals, and knowledge needs, besides its learning and instructional applicability by students and instructors in concrete, online and blended schooling environments.

For applicability(Zook,2017)' it is fortunate that digital curriculum is currently available with several sensory software that enable counselors and teachers to easily locate students outside the school who may need guidance and provide them remediation solutions that could afford the best chance to succeed!

Zook 2017, pp. 2-5 affirmed, that "e-teachers use these digital curriculum solutions to plan out their classes, organize lesson plans, and track student progress. They do it all through an online portal, so everything is right in their web browser. Digital curriculum options come with a full-fledged LMS, complete with automatic grading, data reporting, and abundance of customizable features. With all of these features in one curriculum, teachers can easily identify and help students who need remediation. The key is allowing students to work at their own pace. The idea behind self-paced learning is that students do not have to worry about keeping up with a class or waiting on others. Instead, they learn at the speed that works best for them. As a result, counselor teachers can start identifying students who may need remediation after they complete few assignments".

For curriculum construct, Handan 2018 specified four fundamental elements determinant to its valid and reliable educational identity (Hamdan, Planning Curriculum Document, 2018): goals, knowledge, activities and achievement assessment. They are used according to the following criteria: -

\subsubsection{Curriculum Goals}

The educationally responsive goals should embody student needs such as:

- A person in terms of his/her biological, psychological, behavioral, achievement, moral, history of growth needs and stages, and physical environment needs.

- A productive member in family, profession, free time, and active social volunteer.

- A social public member who is civic citizen in her / his co-existence, adjustment, appreciation, commitment, cooperation, sharing, and involvement (Hamdan, Taxonomy \& Theory of Social Behavior, 2017).

4.3.2 Curriculum Knowledge.

Knowledge embodies the content of curricular goals and objectives. Thus, when derived it should symbolize sufficient details in the content of curriculum goals. This content could be academic, social / cultural, and eclectic contemporary covering diverse events, issues, technologies, and developments.

\subsubsection{Curriculum Activities}

Activities are derived from already specified goals and knowledge. This element is actually the transformational tool of goals and knowledge into the required cognitions, behaviors, values, and skills. Activities could come in different types and forms such as: cognitive, affective, motor, practical, oral, and social; verbal, written, and demonstration; individualized, small groups, and large groups; and, preliminary, developmental / operational and concluding learning.

\subsubsection{Achievements Assessment}

This element is derived directly from curriculum goals, and follows the nature and types of curriculum activities.

Irvine wrote 2017 that curricula still lacks real world lessons in that "real-life experiences can help students develop skills that are often thought to be lacking by employers. However, authentic opportunities to learn what is required in the real world during most students' higher education tenure are missing or offer inadequate systems to structure, measure and assess those applied learning opportunities"'( Irvine, 2017). 
Normally, institutions are assuring that learners are exposed to the basics in key fields of study, but observed that tests and exams deal with low-level knowledge and skills of the discipline within extracts of courses loosely fastened together to constitute programs. Even Course-based essays and senior year courses are somewhat rigorous, but are not sure of preparing students for the real world and offer the precisions of authentic learning.

Educators have a huge wealth of digital knowledge more than they can use or their students need for learning. However, the decisive issue for utilizing the eLearning materials and open educational resources remains in adopting some validating criteria that help faculty evaluate the quality and appropriateness of course materials for students' learning. Examples of these are (Ascione, 2017): material protected by copyright, licensed free use, current, expertly authored and availability when needed for learning.

More software systems, e.g AES (Applied Educational Systems), allow teachers to see how many times a student has attempted a test (if have instructions to do so). With this information, teachers can see which students are getting better, which are persistin on a steady grade, and which are getting worse ${ }^{17}$.

Regardless, digital curricula enable teachers identify the students having trouble so can approach them directly and remediate their learning problems through offering extra help during class sessions, Private discussion, or simply advise students to repeat the curriculum materials using different way ${ }^{17}$.

In addition, several universities in the United States have programmed software to enable teachers to online monitoring their student's performance. Further, with massive availability and usability of data as done by "Stanford's Lytics Lab", and the Open-Learning Initiative of the"Carnegie Melon University and the Check-My-Activity-Tool of the University of Maryland", students are able to monitor their own performance and adapt it according to result (Zook.2017).

The widespread of "Blend-Digit" education through MOOCs and possible others materials in near future, the human race has not only freed learning to infinity by means of cognizing, thinking, schooling, scientific research, and professional advancements, but also achieving them free of cost. Hence, there will be no excuse for any individual, group or community to claim illiteracy of any knowledge since it is available in huge varieties and quantities online more than they can use.

\subsection{The "neoBlend-Digit" counseling Resource Room/ Hall}

The blended counseling resource room coupled with its twin the educational connected clinic ${ }^{19}$ are the fourth factor, which determines the concept and practice of the new approach to education that is the "neoBlend-Digit" schooling. Next paragraphs presents various features, which comprise the professional identity of the blended counseling resource room /educational clinic.

\subsubsection{Concept and Role of the Educational Connected Clinic}

The educational clinic is the central unit within schooling facilities, which hosts both teachers and visiting students who seek psycho - educational consultation, counseling and appropriate prescriptions for the treatment of learning / behavioral needs.

The present facility is a reformed layout of the "connected classroom" that just started in education. While the conventional classroom serves one or two purposes in schooling namely large groups teaching and learning, the educational clinic hosts several functions, such as (Figure 3):

- A mini research center in which students' information is mainly gathered, analyzed and interpreted.

- A conference room in which students, individually and as small groups, meet clinical personnel and discuss together the nature and roots of their needs, and develop as a result educational / behavioral prescriptions which aim at satisfying the observed needs.

- A consultation counseling center in which students seek the professional advice of teachers and other clinical school personnel to overcome specific problems or to understand the causes and cures of their personal or study needs.

- A materials' development mini-center in which students' prescriptions, simple software materials like handouts, sketches, limited drawings, and action plans are drawn.

- An instant learning, practicing and experimentation center in which students may try out 'when necessary' to apply new concepts, methods, and techniques, tools or procedures related to their achievements and personal developments.

- A specialist conference room in which teachers and other clinical personnel could meet to discuss emergent matters concerning the education of students or to exchange views regarding some of their personal/behavioral cases.

- An evaluation center in which needs are studied, desired outcomes are projected, plans and prescriptions are drawn, learning and behavioral actions and achievements are measured against specified standards. 
- An educational / behavioral administrative center by which students individually and as small groups are referred to different clinical specialists and facilities in order to provide specific data related to their needs ; to be advised about new learnings, behavioral, personal, social or economic difficulties; to learn a concept /a skill or modify a personal act.

\section{What Are the Nature and Content of Curriculum Design for "neoBlend-Digit" Multi-Stage Schooling?}

\section{Spiral Curriculum Design for "neoBlend-Digit” Multi-Stage Schooling}

Spiral curriculum design is composed academically of serial connected loops, each represents a course, a topic or a subject within a learning sequence leading at the end to achievement of a course, a class grade, a stage, or a BSc., Master's or PhD. Degree as the case of higher education (figure 3). The developmental design for "non-failing "neoBlend-Digit" Schooling" adopted the Spiral Cognitive Model developed by Jerome Brunner 1960 since the inductive interconnected content of courses from year to year helps students comprehend meaningfully the materials and reinforce positively the required learning.

Actually, the curricular nature and functions of the developmental design for "neoBlend-Digit" schooling are closely designed in accord of next Brunner's principles (Harden, 1999; Johnston, 2012 :

- The student restudies a topic, theme or subject several times throughout school consequent stages and grades;

- The complexity of the topic or theme increases with each restudy;

- New learning has a relationship with previous learning and is put in context with the old information.

- The information is reinforced and solidified each time the student restudies the subject matter;

- The spiral curriculum allows a logical progression from simplistic ideas to complicated ones; and

- Students are encouraged to apply the early knowledge to later course objectives.

Accordingly, it could be observed in current spiral Design, inter-related consequent loops of gradually increasing knowledge within related school grades and stages that resemble Brunner's above principles.

Technical illustrations, Due to space restrictions and to avoid extended details, the article presents four examples that explain the nature and content required for each. Individual schools have total freedom to add, drop or modify the “examples' contents" to be more responsive to their own educational conditions and priorities.

Moral dilemmas of current time, as World societies are suffering from overwhelming violence, local bloody civil wars, destructive foreign interventions, and wide spread corruption, it appears highly necessary to expose school generations to a curriculum core concerned with civic citizenship, social behavior, ethics, democracy and human rights. Japan and other contemporary advanced countries advocate strongly long years ago this type of learning in their schooling (Smith, 1948; Maruko, 2014).

Generations, when concentrate on achieving knowledge, motor skills and motor movements without having sufficient affects, e.g. values, feelings, moralities and wisdom, could turn their nation states, societies and school communities into massive emotionless dull populations similar computer machines which are stuffed with endless cognitive data, but when asked by students the computer gives them data for brains but never or rarely the sensation of passions, emotions, and the nobility of peaceful human associations.

However, in other extreme cases of schooling where over emphasis on poor and outdated knowledge, school communities may turn into ignorant primitives who lack reasoning, tolerance, peaceful communication and interaction with others. Immoral or corrupted nation states in this regard seem fond of bloody civil wars, political oppressions, and apt to annexation and marginalization by other states. Or worse yet are attacked by savage groups who committed massacres and dismantled the long splendid history of human heritage like what happened recently in Afghanistan, Iraq, Syria, Libya and Yemen.

It is deep sorrow for world societies, that above cases are prevailing daily norms anywhere in the Globe! Evidently, educating societal generations "affects" or civics is not commended by school systems.

While schooling encompasses generally three macro stages: kindergarten school that include infancy and nursery in early education; elementary school that holds lower and upper stages; and high school, which consists of junior and senior high stages. In addition to undergraduate and graduate stages of higher education. However, when learning and teaching the required subjects or courses of "neoBlend-Digit" programs, it is important to note the following principles and procedures are applied:

- The study system is quarter credit hour.

- The study methods are interchangeably blended and online, whenever either deems more suitable. 
- School councils are strongly recommended to form students' governments (SSGs) for each school stage 1 through 12 grades. These SGs are elected directly by students and teachers of the concerned stage. SG's cabinet and members share the decision-making processes with nondirective school personnel and peers who offer collaborative standby consultations for implementation and self and peers' achievements' reviews and assessments.

- The types and quantities of subject content are enlarged gradually every year of each stage. Principles of connectivity, continuity and relatedness should be applied here.

- The required subjects in each school year are distributed among the three quarters by instructional staff through close coordination with students and/ or the student school government of the stage or grade levels.

5.1 Tentative Program for Lower Elementary School- $3^{\text {th }}$ Grade

Lower Elementary School includes three grades: first, second and third grades.

From data of second grade

Entrance to diagnostic exams for third grade

\subsubsection{Academic General Core}

National language5 (NL5), foreign language5 (FL5), elementary math5 (EM5), elementary science5 (ES5) elementary ICTs5 (EICTs5) environmental health5 (EH5).

\subsubsection{Ethical - Social Track}

None violence behavior3 (NVB5), elementary human rights3 (HR5), social behavior3 (SB3), volunteering \& sharing 3 (VS3)

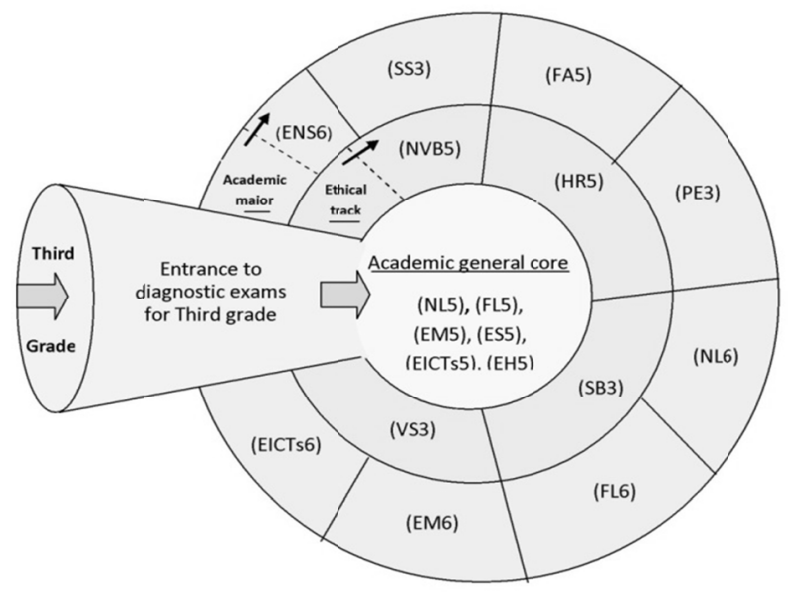

Figure 6. Tentative Spiral Curriculum Design for"neoBlend-Digit”Third Grade Schooling

\subsubsection{Academic Major Core}

Elementary science6 (ENS6), elementary social studies3 (SS3), fine arts3 (FA5), Physical Edu.3 (PE3) national language6 (NL6), foreign language6 (FL6), elementary math6 (EM6), elementary ICTs6 (EICTs6).

\subsection{Tentative Program for Upper Elementary School- $6^{\text {th }}$ Grade}

Upper elementary school includes three grades: fourth, fifth and sixth grades.

From data of fifth grade

Entrance for diagnostic exams for sixth grade 


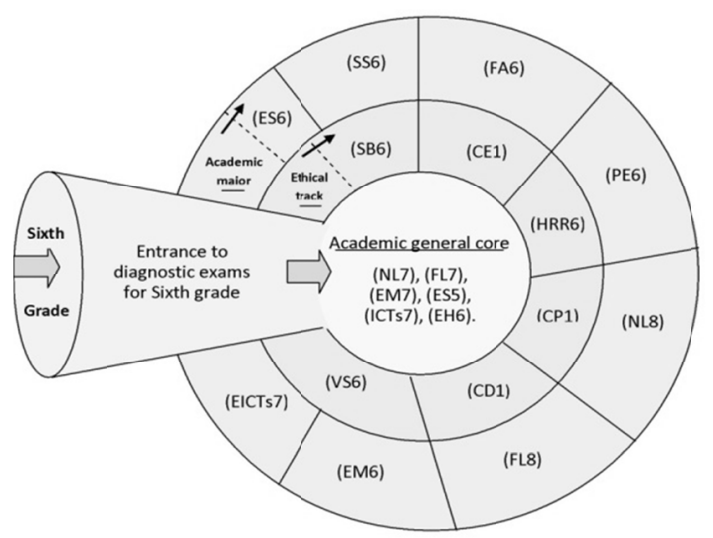

Figure 7. Tentative Spiral Curriculum Design for "neoBlend-Digit" Sixth Grade Schooling

\subsubsection{Academic General Core}

National language6 (NL6), foreign language6 (FL6), elementary math6 (EM6), schooling elementary ICTs6 (EICTs6) environmental health6 (EH6).

\subsubsection{Ethical - Social Track}

Social behavior6 (SB6), citizenship education1 (CE1), human rights and responsibilities6 (HRR6), civic personality 1 (CP1), civic democracy1 (CD1), volunteering \& sharing 6 (VS6).

\subsubsection{Academic Major Core}

Elementary science6 (ES6), elementary social studies6 (SS6), fine arts6 (FA6), Physical Edu.6 (PE6) national language 7 (NL7), foreign language7 (FL7), elementary math6 (EM6), elementary ICTs7 (EICTs7).

\subsection{Tentative Program For Junior High School- $9^{\text {th }}$ Grade}

From data of eighth grade Entrance diagnostic exams for ninth grade

\subsubsection{Academic General Core}

National language9 (NL9), foreign language9 (FL9), junior math9 (JM7), junior science 9 (JS9), junior ICTs9 (ICTs9), philosophy \& logic3 (PL3), scientific research3 (PSR3)

\subsubsection{Ethical - Social Track}

Citizenship education2 (CE2), human rights and responsibilities 9 (HRR9), civic personality 2 (CP1), civic democracy2 (VD2), Electronic Democracy1 (ED1), volunteering9 (V9)

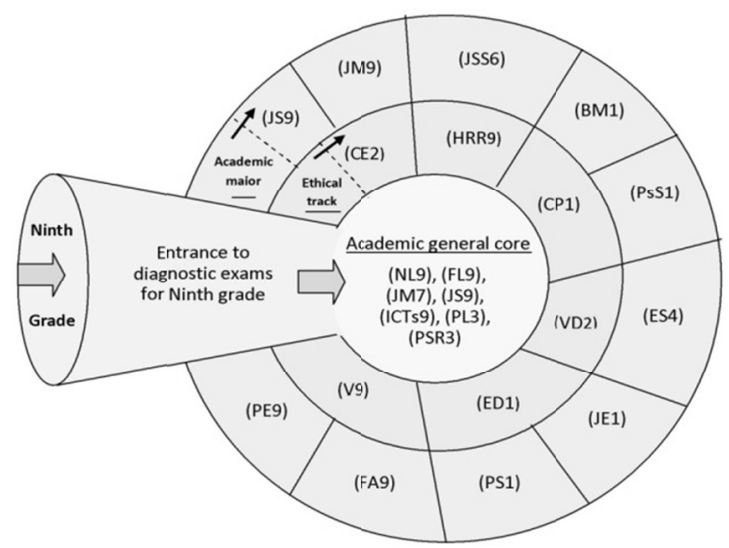

Figure 8. Tentative Spiral Curriculum Design for “neoBlend-Digit”Ninth Grade Schooling

\subsubsection{Academic Major Core}

Junior science9 (JS9), junior math9 (JM9), junior social studies6 (JSS6), business management 1 (BM1), psychological studies1 (PsS1), education studies1 (ES4), Junior economics1 (JE1), political studies1 (PS1), fine arts9 (FA9), Physical Edu.9 (PE9) 


\subsection{Tentative Program for Senior High School- $12^{\text {th }}$ Grade}

From data of eleventh grade

Entrance diagnostic exams for twelfth grade

\subsubsection{Academic General Core}

Senior science12 (SS12), senior math12 (SM12), fine arts7 (FA7), Physical Edu.5 (PE5), senior economics (E1), political studies1 (PS1),

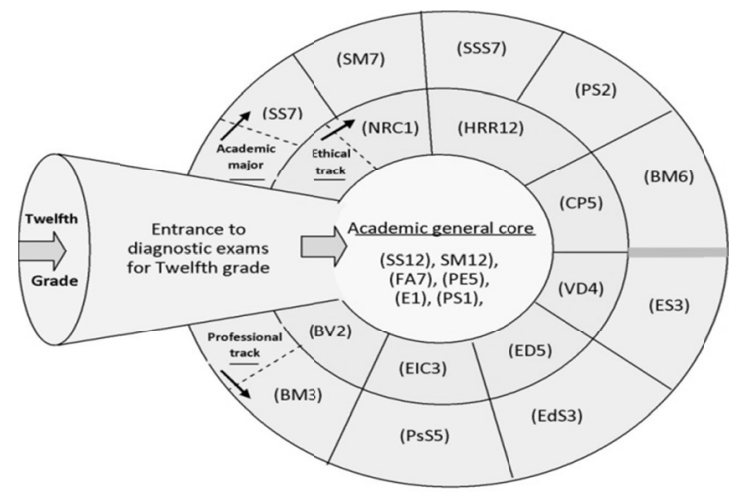

Figure 9. Tentative Spiral Curriculum Design for"neoBlend-Digit”Twelfth Grade Schooling

\subsubsection{Ethical - Social Track}

National, regional and global citizenships1 (NRC1), human rights and responsibilities 12 (HRR12), civic personality 5 (CP5), civic democracy4 (VD4), Electronic Democracy 5(ED5), Ethics, integrity and conduct3 (EIC3), volunteering 2 (BV2).

\subsubsection{Academic Major Track}

Senior science7 (SS7), senior math7 (SM7), senior social studies7 (SSS7), political studies2 (PS2), business management 6 (BM6), psychological studies6 (PsS6), education studies4 (ES4).

\subsubsection{Professional Preparation Track}

Business management (BM3), psychological studies (PsS5), digital education studies (DES3), economic studies (ES3). Electronic equipment maintenance3 (EEM3) .

\section{What Are the Methods, Techniques and Quality Issues of "neoBlend-Digit" Schooling?}

\section{Methods, Techniques and Quality Control Issues of "neoBlend-Digit" Schooling}

Today "neoBlend-Digit" Schooling (neoBDS) is being materialized due to ICTs accelerating developments, which are in nature objective, digital, concrete, behavioral, practical and empirically measurable. Hence, verifiable individual and small groups techniques should be maintained for implementing and assessing neoBDS effects. Examples of these techniques are apprenticeship, learning by doing, field training, medical internships, laboratory studies, modeling, demonstration, presentation, group projects, case study, laps, experimentation, cooperative and collaborative learning, workshop, and problem-based learning (Bates, 2015, Hamdan, RE-SCHOOLING SOCIETY 2016).

6.1 Methods and Techniques of "neoBlend-Digit" Schooling

Several primary methods are used for implementing "non-failing "neoBlend-Digit" schooling", briefly they are (Bates, 2015)

Methods: Guided Independent Study, Small Groups Methods, and Field Study Method.

For techniques of "neoBlend-Digit" Schooling, a sample of contemporary ones, are: Micro-learning, Mobile, Video, Artificial Intelligence (AI), Augmented Reality (AR), online Reality (VR), Subscription learning, Personalized learning, Performance Support, Spaced Learning, Social media, performance Accountability, Immersive Learning, Interactivity learning, Chat Context, Modern Professional Learning, Learning Engineering, Applicability, HumanCentered Design, Gamification, Curation, Live Streaming Video, accelerated Certification, Adaptive Learning.

\subsection{Operational Mechanisms of "neoBlend-Digit" Schooling}

These mechanisms include the following examples. 


\subsubsection{Human Services of "neoBlend-Digit" Schooling}

Student Family, Personal Tutors, Curriculum and Instruction Specialists, Online Education Specialists and Technicians, Educational Assessment Specialists, School Psychologists, Student Counselors, Social Workers, Clinical - Educational Aides, Blended Facility Specialists and Technicians, Physicians and Medical Analysts, Recreational Specialists, School Administrators, Logistics and Supplies Officers

\subsubsection{Primary Facilities of "neoBlend-Digit" Schooling}

Blended tutorial center, instructional digital telephone service, computer information center, educational pharmacy, academic internet cafés, academic blended auditorium, blended learning laboratories, digital equipment sales, and maintenance center, and digital internet and laptops gadgets sales center.

6.2.3 Management Quality Issues for Promoting “neoBlend-Digit” Schooling (Stansbury, 2010)

- "Information security

- Student success and completion

- Data-informed decision-making

- Strategic leadership

- Sustainable funding

- Data management and governance

- Higher education affordability

- Sustainable staffing

- Next-generation enterprise IT

- Digital transformation of learning"

7. What Are the Possible Learning Achievement Tracks for Non-Failing "neoBlend-Digit" Schooling? Trio - Learning Achievement Streams for Non-Failing “neoBlend-Digit” Schooling

Three logical assumptions underlie these three proposed achievement alternatives in regard to learning of curriculum content. These are (Hamdan, The Countenance of Info- Communication Technologies 2016):

1- Different students have different academic aptitudes for variant levels of learning. e.g. high, normal and low.

2- Different students have different academic and professional needs for learning any subject matter, e.g. literacy, profession and academic distinction.

3- Different students have different learning paces. e.g. quick, normal and slow.

The current ICTs' accelerating developments have reinforced the principle and practice of the newly accredited studentcentered approach in schooling. Further, personalized learning and a better understanding of students by educators are being explored in Issues such as student different natures, backgrounds, needs, cognitive abilities, aptitudes and learning paces, among others. These psych- educational issues coupled with ICTs abundant knowledge, tools and skills available for educational personnel, are enabling:

- Curriculum and instruction specialists to break down the macro curricular document into average and micro learning and teaching units, which could be achieved without apparent difficulties by $90 \%$ of students with $90 \%$ A and B grades. This task will lead mainly to producing appropriate instructional units that will focus on basic required learnings.

- Source teachers and educational psychologists to counsel students on their preferred study goals, choices and achievement levels of each subject matter or textbook. This task will enable individual student to take appropriate decisions for:

- Achievement contents and contracts for studying course levels(figure9), 


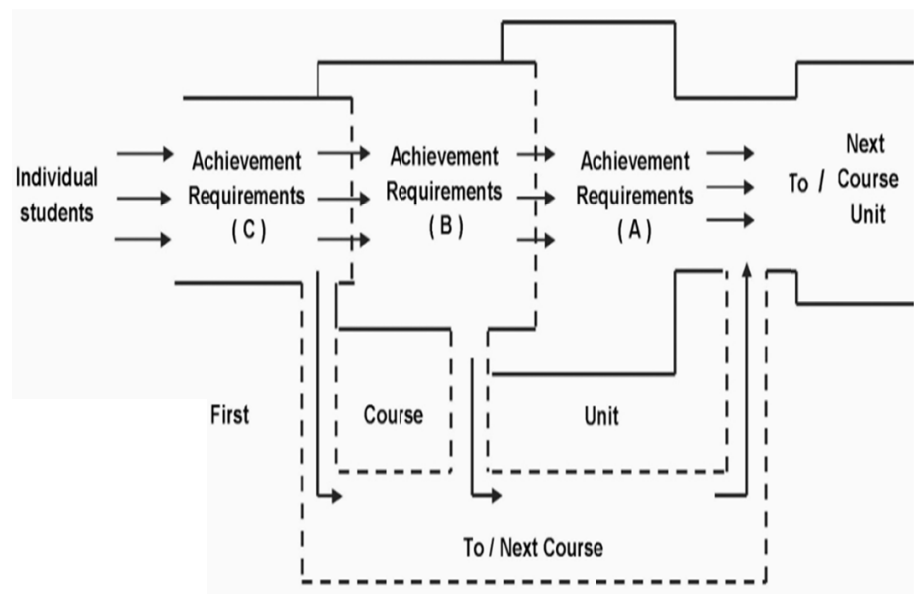

Figure 10. Differentiated three curriculum-learning levels for grades $\mathrm{C}, \mathrm{B}$ and $\mathrm{A}$

- Study goals of each course. e.g. for literacy in curriculum topic, professional works or pioneering in academic and professional fields (figure19).

- Assessment types, procedures, tools, exams, tentative time schedules and criteria for successful achievement. Diagnostic pre-learning, formative, and summative assessments are of main mutual comparable concerns here.

- Educational "neoBlend-Digit" technologists to coordinate with curriculum and instruction specialists and educational psychologists to determining types of ICTs, which suit each learning and instructional task. An "implementation roadmap" or "Technology Roadmap"( University of Cambridge. n.d.; Wikimedia Foundation. 2016) could be drawn here and copies are to be delivered to all concerned schooling personnel for individual student's learning.

- Human support and follow up services of students' learning. Examples of these, are subject matter counselor teachers, student advisors, curators or operators of an online and blended library, online technicians of internet lines and equipment connections, operations, software apps., 24/24 emergency repairs, database security, programs protection, among others.

Moreover, having school subjects redesigned into micro and medium learning/ instructional units, individual students and/ or self-selected small groups will be ready to assume their blended and online paced learning in accord to both selected achievement grades: C, B, or A (figure10) and future professional needs (figure11): academic literate (general knowledge of the subject), specialist workers (e.g. teachers, engineers, chemists, or social workers and others), or academic pioneers (e.g. social leaders, reformers, thinkers, scientists, inventors and theorists).

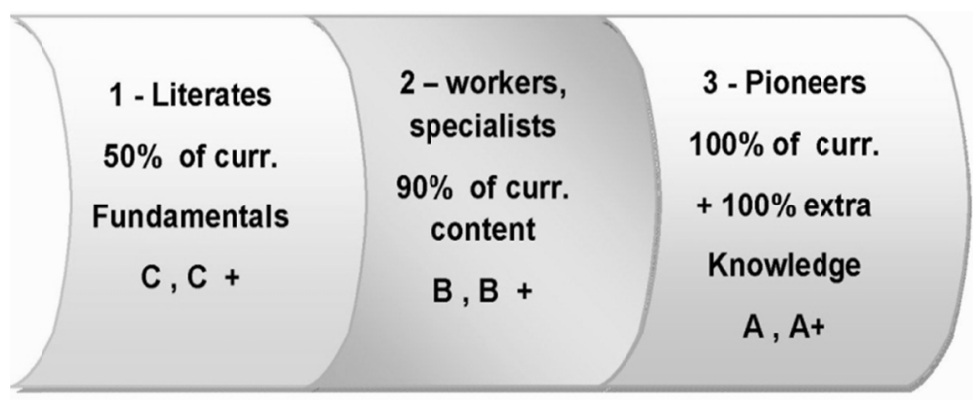

Figure 11. Learning the Curriculum at Multiple Achievement Levels- Literates, Specialists, and pioneers

Next level of learning focuses on subjects common to which students move individually and in small groups to learn according to their desire or work needs. While this element coupled with the core determine the academic nature of curriculum, it prepares students for professional and specialist roles.

Finally, the peripheral knowledge which serves as complimentary details of curriculum content coupled with the basics and the commons will be taken by superior and gifted students (the future pioneers in curriculum subject) plus selected extra academics from related resources. 


\section{What is from school systems to empower the newly utilized ICTs equipment and software is of two folds:}

1- To apply ICTs inventions seriously and scientifically in schooling without much propaganda and little practice on the ground as observed by many environments, it is recommended from education systems in this regard, to:

- initiate case studies of similar issues in other countries,

- implement quick but thoughtful 'hothouse' trials and well-planned field experimentations to examine the validity and reliability of ICTs products, then perform needed customizations and preparations to fit the nature and demands of local schools.

2- Invest ICTs for producing schooling change beyond the non-conventional daily routine manner. ICTs innovations are endless and constantly flowing. In the meantime, schooling is a flexible applied task to conduct that allows for more differentiated practices as students differ in personal growth, work specializations and progress needs.

Besides, when considering integration of ICTs in schooling, it is highly necessary to examine the implications of factors such as school age, study stage k- 12 up to higher education, methodology, curricula, and facilities for successful "neoBlend-Digit" schooling. Hence, schooling goals, textbooks, methods, assessment, facilities, equipment, and services should be continually reviewed and reformed with no delay or pre-imposed subjective conditions that may hinder the welfare of students' development.

\section{How Could Futuristic "neoBlend-Digit" Learning Be Open to Infinity?}

\section{Futuristic "neoBlend-Digit” Learning Open to Infinity (nBDLOI)}

The present Third Millennium could be nicknamed the "Age of Nudity" due to ICTs profound remote digital penetrating power into the deep privacy of human anatomy, actions, family and daily lives.

In education, families, resource teachers or students' counselors can by a click at the digital curriculum, reveal where every learner's location, how many times attempted reading, performing assignments, or what study difficulties they are facing.

Consequently, this author sees no need for students' unified study schedules nor for compulsory school attendance. Individual counseling needs could be programmed at specific times and dates. Students continue as such until they graduate with their required degrees.

It may follow that school and university facilities and equipment could in whole or in part be transformed and utilized in establishing continuing and professional training and development centers, hobby innovative laboratories, behavioral rehabilitation clinics, community centers for discussion of urgent events or issues. Thus, learners and learning endeavors have more choices to free development goals to infinity. The ultimate period for performing and disseminating of these "neoBlend-Digit" alternative replicas to realize application breakthroughs in schools and universities is around five years while undeveloped and developing environments need between 15-20 years due to observed time lapse between launching educational innovations in developed contexts and the developed/developing school systems start examining and expirementing the emerging renewals.

With "neoBlend-Digit" students can learn and achieve (if he/ she decides) anything at any time and place whether young or adult, female or male, working or out of work, normal or abnormal, city resident, rural, sandy or icy deserts. There is no excuse for any person in the nBDLOI era to being illiterate or cannot advance her/his personal and pfofessional future.

This author sees the nBDLOI Age as the era of "knowledge infinity". World societies and institutions have information, good and bad more than they need or use. The big problem facing school and university generations is not in the huge good knowledge available but in the immense offensive information and adjacent services that counteract the effects of positive knowledge. Hence, a cardinal concern of nBDLOI is immunizing generations against destructive consequences of "bad info" on human cognition, moralities, and civic social behavior. Rosenberg 2017 called strongly school systems and institutions to comply and take control of learners data before it is too late. For this purpose, he invented a "LEARNING LOCKER- GDPR" software to safeguard studentsand educational information from hacking.

\subsection{Alternative One}

It is expected in the near future, by the forties of this third Millennium (Schilling, 2013) at the most, to have "neoBlendDigit" learning schools that are open around the clock for individual and small group students in a limitless number. Students could decide individually to pursue a specific career, profession or specialization. She or he may launch the online search for programs that satisfy their study needs. While they can decide for themselves on the appropriate course of study, they could also seek peers' opinion support and nondirective counseling from a resource teacher/instructor. 
As students, finish this foundational preparation step, they register the program at the concerned school, training center, or university to earn a tentative formal recognition or credibility. Then, they could initiate their required programs individually and independently with some collaboration with close peers and limited counseling and follow-up from a resource instructor. At the end of required learning, each student organizes her/his blended program's assignments and achievement documents in a portfolio for presenting to an instructor who is assigned jointly with individual students 'themselves' to review and assess the achievement portfolio and graduation.

\subsection{Alternative Two}

This learning alternative is a shortcut and more advanced way for students to learn and achieve the purposes they need to realize, which is composed of three achievement streams: subject literacy, work career, or specialty pioneering. Qualified students to pursue current study alternative are highly literate in digital technology, the subject matter, interindependent personality, self-management, and have special aptitude and passion for the subject.

Individual students here have open responsibilities with or without the prior consent of school or university authorities, to choose, design, develop or modify and carry out the study programs of their choices whether these learning activities belong to school grade, stage or certification; B.Sc. courses or degree, MSc. courses and thesis, Ph.D. courses and dissertation.

The cordial advice provided to them at this stage is to consult the contents and instructions of the chosen program or degree, or similar ones applied by other local or transnational institutions, then to examine their achievements against the criteria specified by the original program or degree, or by other similar cases.

For crediting the performance of individual students for graduation and presuming public or private careers, each one launches a careful task of grouping and organizing in a meaningful way all written, audio and electronic documents whether belong to readings, activities, assignments, reports, reviews, achievement exams, interview A/V records, her/his observations, critiques and comments for summative review, quality assessment and judgmental decisions for each study case.

A specialized panel or committee composed of 2-3 competent schoolteachers or university faculty members are officially delegated for reviewing and accreditation of student's achievements.

\subsection{Epilogue}

This article presents a methodology of "neoBlend-Digit" schooling which is highly responsive to the various needs, conditions, and professional responsilities of learners and teachers. It is self- independent mechanism, which provides a total freedom to students to decide plan and implement learning tasks at times and locations of their individual choices.

The framework of "neoBlend-Digit" schooling utilizes heavily the following concepts, principles and procedures:

- learners centered paradigm

- "Blend-Digit" Schooling of 1-12 grades to BSc studies.

- Functional factors/tools, as instructional counselors, support services, study plans and courses, micro curricular units, micro counseling/instructional units, micro e-learning units, internet equipments and peripherals, blended classrooms, and blended school facilities.

- Working methodology, which includes none-directive schooling; students as self teachers; students' initiaters of learning; systemic diagnostic, formative and summative schooling; trio-learning achievement streams; interindependent collaboration; individual and small group learnings; blended projects; and personalized learning.

- Meta quality assessment of inputs, processes and outcomes of "neoBlend-Digit"schooling.

However, the quality of any product or project including the "neoBlend-Digit" methodology is dependendet upon two factors: the engagement of human services who keep learning and instruction live and productive, and program's maintenance of knowledge and skills of human services by means of in-service professional training and development.

For engagement, most research confirmed its decisive role in keeping the program's mission active, progressing and productive (Mansfield.edu. 2012; OBryan and others. 2013; Umbach and Wawrzynski, 2005). Inservice monitoring and maintenance of faculty professional needs are a "must" for schooling and school systems. This renewal task encompasses both the teaching faculty and adjunct services, if "neoBlend-Digit"schooling is intended to be stable, consistent and effective for students' learning (Bates, 2016).

Finally, despite the pessimistic observations regarding the slow reformation of schooling in light of ever revolving ICTs inventions, introducing the "neoBlend-Digit" methodology as a steering framework will lead to thoughtful renewals that will free schooling from incompetent conventional teachers and services, thus unleashing students' powers for learning to infinity. 


\section{References}

Allen, E., \& Seaman, J. (2007). (Co-Director, Babson Survey Research Group, Babson College the Sloan Consortium). Online Nation-Five Years of Growth in Online Learning. https:/onlinelearningconsortium.org/survey_report/2007-online-nation-five-years-growth-online-learning/

Allen, E., Seaman, J., \& Others. (2016). Online Report Card-Tracking Online Education in the United States. https://onlinelearningsurvey.com/reports/onlinereportcard.pdf

Androulla, V., \& McAleese, M. (2014). High-Level Group on the Modernization of Higher Education-New modes of learning and teaching in higher education. http://ec.europa.eu/dgs/education_culture//library/reports/modernisation_en.pdf

Anthony, W. (Tony) Bates. (2016). Teaching in a Digital Age. Licensed under a Creative Commons Attribution-Non Commercial $4.0 \quad$ International License. https://teachonline.ca/sites/default/files/pdfs/teaching-in-a-digital-age_2016.pdf

Ascione, L. (2017). 7 musts for digital and OER course materials. http:/www.ecampusnews.com/curriculum/musts-digital-course-materials/?ps=mzhedu\%40gmail.com/

Barbara, I. D., \& Carrie, E. R. (2003). Leadership, Higher Education, and the Information Age: A New Era for Information Technology and Libraries. https:/www.google.jo/

Barnes \& Noble College Insights (2017). Achieving-Success for Non-Traditional-Students. https://www.bncollege.com/Achieving-Success-for-Non-Traditional-Students-01-11-17.pdf

Bates, A. W. (Tony). (2015).Teaching-in-a-Digital-Age. Educational Technology.

Bates, A. W. (Tony). (2016). Chapter 3: Methods of teaching: campus-focused: 3.5 Apprenticeship: learning by doing (1) $0 \quad 3.5 .4 \quad$ Apprenticeship in $\quad$ online learning environments. https://opentextbc.ca/teachinginadigitalage/part/chapter-4-methods-of-teaching/

Cromwel, S. (2015). The School of the Future. The Guardian News and Media. https://www.theguardian.com/teacher-network/series/schools-of-the-future

Davis, Van L. (2017). Predicting the next 20 years in higher ed. reveals 5 major themes. ECAMPUS NEWS. https:/www.ecampusnews.com/campus-administration/8-predicting-higher-ed-5-themes/

Dewey, B. I., \& Regenstein, C. E. (2003). Leadership, Higher Education, and the Information Age: A New Era for Information Technology and Libraries. https://www.google.jo/

Emma (2016). Europeanmoocs.eu Mobile Usability: 85/100http://europeanmoocs. eu/blog/

Floridi, L. $\left(2018^{\mathrm{a}}\right)$ Soft Ethics and the Governance of the Digital. Springer, Philos. Technol. https://doi.org/10.1007/s13347-018-0303-9

Floridi, L. $\left(2018^{\mathrm{b}}\right)$. Fake news and a 400-year-old problem: we need to resolve the 'post-truth' crisis. The Guardian. https:/www.theguardian.com/technology/2016/fake-news-echo-chamber-ethics-infosphere-internet-digital

Hamdan, M. Z. (1988). Clinical Education. Damascus: Modern Education House. www.hamdaneducation.com (in Arabic)

Hamdan, M. Z. (1999). Reschooling Society- With a Clinical Personalized Appraoch. Damascus: Modern Education House. www.hamdaneducation.com

Hamdan, M. Z. (2014). A Paradigm of Transnational Collaborative neo-Blended Learning: toward an exchange theory of growth need - responsive source transactions. Paper presented to the 13th European Conference on e-Learning ECEL-2014 being held at Aalborg University, Copenhagen, Denmark on the 30-31 October.

Hamdan, M. Z. (2015). Blended Achievement in Transnational Schools as Collaborative Learning Communities- Toward a Systemic Assessment Framework. International Journal of Modern Education Research. Vol. 2, No 6, November 2015, pp88-97

Hamdan, M. Z. $\left(2016^{\mathrm{a}}\right)$. The Countenance of Info- Communication Technologies- Re-Inventing the Quality of Future Schooling. Paper presented to the 4th International Conference on Modern Education (ICOME 2016) held Sept. Florida, U.S.A 19-22, 2016

Hamdan, M. Z. $\left(2016^{\mathrm{b}}\right)$. Re-Schooling Society in the Info Global Age. Damascus: Modern Education House, Online Edition. Education-booksonline.com/ 
Hamdan, M. Z. $\left(2016^{c}\right)$. Re-Schooling Society with a Clinical- Personalized Approach in the Info Global Age. Damascus: Modern Education House, Online Edition. Education-books-online.com/

Hamdan, M. Z. (2017). A Multiphasic Blended Citizenship Acculturation Program for Building Diverse Citizens in Hostile Political Times and Contemporary ICT- Global Age. GLOBAL AGE. European Journal of Education Studies, 3(10).

Hamdan, M. Z. (2017). Taxonomy \& Theory of Social Behavior- Toward a Scientific Framework for Studying \& Developing Human Communication. Damascus: Modern Education House. www.hamdaneducation.com

Hamdan, M. Z. (2018). Planning Curriculum Document- from Needs Assessment, Development, Implementation, to Quality Evaluation. Damascus: Modern Education House, www.Online Edition. Education-booksonline.com/

Hamdan, M. Z. (Member, Panel Discussion). (2018. February 9). Violence and Civic Education in School Curriculum. AL- Hurrah T.V. Producer, George Chawah.

Hamdan. M. Z. (2017). Information Technologies in Blended School Education. Online edition, modern Education House. www.hamdaneducaion.com/

Harden, R. M., \& Stamper, N. (1999). What is a spiral curriculum? Medical Teacher, 21(2), https://doi.org/10.1080/01421599979752

Hayes, W. (2006). The Progressive Education Movement: Is it Still a Factor in Today's Schools? Rowman \& Littlefield Education. https://eric.ed.gov/?id=ED494126

Hideki, M. (2013). Moral Education in Japan. https://www.nier.go.jp/English/educationjapan/pdf/201303MED.pdf

Howard, J. (2012). The Spiral Curriculum. http://oregongearup.org/ research-briefs/spiralcurriculum.pdf

Irvine, G. (2017). 4 reasons why a generational skills gap exists today-and isn't closing. http://www.ecampusnews.com/curriculum/generational-skills-gap-exists

John, N. (2013). The New Digital Age by Eric Schmidt and Jared Cohen - review. Guardian and Observer. https://www.theguardian.com/books/2013/apr/29/digital-age-schmidt-cohen-review

Johnston, H. (2012). The Spiral Curriculum. Research into Practice. https://files.eric.ed.gov/fulltext/ED538282.pdf (Harden and Stamper,1999)

Lorenzetti, J. P. (2014). Thinking Horizontally and Vertically About Blended Learning. https://www.facultyfocus.com/articles/blended-flipped-learning/thinking-horizontally-vertically-blended-learning/

Mami, M. (2014). With ethics classes receiving upgrade in 2018, worries of nationalism rise. https://www.japantimes.co.jp/news/2014/11/24/reference/ethics-classes-becoming-mandatory-2018-

Mansfield.edu. (2012). Twelve Best Practices for Student Engagement and Retention. https://www.mansfield.edu/academic-affairs/upload/Twelve-Best-Practices-for-Student-Engagement-and-Retention -2012.pdf

Maruko, M. (2014). With ethics classes receiving upgrade in 2018, worries of nationalism rise. https://www.japantimes.co.jp/news/2014/11/24/reference/ethics-classes-becoming-mandatory-2018

Miyasaka, M., \& Others. (2014). An international survey of medical ethics curricula in Asia. http://jme.bmj.com/content/25/6/514

Nazeeri, F. (2018). Most institutions developing online programs have it all wrong-here's how to do it right. ECAMPUS NEWS. https://www.ecampusnews.com/eschool-media/online-learning-3-b/?

OBryan, A., \& others. (2013). Establishing an Online Professional Learning Community to Promote Faculty Engagement and Excellence

Online Learning Consortium. (2017). Over six million students now enrolled in distance education. https://onlinelearningconsortium.org/news_item/new-study-six-million-students-now-enrolled-distance-education/

Rose, T. (2016). The End of Average: How We Succeed in a World That Values Sameness. https://www.amazon.com/End-Average-Succeed-Values-Sameness/dp/0062358367

Rosenberg, M. (2017). Ensure compliance \& take control of your learner data before it is too late. LEARNING LOCKER-GDPR

APP. https://www.learningsolutionsmag.com/author/marc-rosenberg/https://www.ht2labs.com/learning-locker/apps/gdpr -app/?utm_source=learningsolutions 
Schilling, D. R. (2013). Knowledge Doubling Every 12 Months, Soon to be Every 12 Hours. http://www.industrytap.com/knowledge-doubling

Semel, S. F., \& Sadovnik, A. R. (2008). The Contemporary Small-School Movement: Lessons from the History of Progressive Education. Teachers College Record, v110 n9 p1744-1771 2008. https://eric.ed.gov/?id=EJ825746

Smart, K. L. (2007). Learning by Doing: Engaging Students Through Learner-Centered Activities. https://doi.org/10.1177/10805699070700040302

Smith, T. V. (1946). Ethics in the Japanese Educational Curriculum. The University of Chicago Press., 56(4), (Jul. 1946), 297-302. https://doi.org/10.1086/290518

Stansbury, M. (2010). Boost Student Achievement with Connected Teaching, Next Generation Collaboration, Top News. Nov 18th, 2008. http:sessions,/www.eschoolnews.com/

Stansbury, Y. M. (2017). Educause: The top 10 IT issues, trends and technologies of 2017. http://www.ecampusnews.com/featured/featured-on-ecampus-news/educause-10-issues-2017/?a

The Foundation for Blended and Online Learning. (2017). Why do students choose blended and online schools? The "end of average" requires personalized learning environments. www.blendedandonlinelearning.org/.

Umbach, P. D., \& Wawrzynski, M. R. (2005). The Role of College Faculty in Student Learning and Engagement. https://link.springer.com/article/10.1007/s11162-004-1598.

University of Cambridge. n.d. Road mapping for Strategy and Innovation. www.ifm.eng.cam.ac.uk/uni/.Retrived April, (2016. And.

Vassiliou, A., \& McAleese, M. (2014). High Level Group on the Modernization of Higher Education-New modes of learning and teaching in higher education. http://ec.europa.eu/dgs/education_culture/repository/education/library/reports/modernisation_en.pdf

Vassiliou, and McAleese, (2014). Magyar, Balint. 2016. School of Future. www.om.hu/

Warlick, D. (2016). Educationinis. https://educationinis.wordpress.com/2016/05/05/45/

Wikimedia Foundation. (2016). Technology Roadmap. Retrieved April, 2016. https://en.wikipedia.org/wiki/Technology_roadmap\#7

Zook, C. (2017). How to remediate CTE students with digital curriculum. https://www.aeseducation.com/blog/4-steps-to-remediate-students-with-digital-curriculum/

\section{Copyrights}

Copyright for this article is retained by the author(s), with first publication rights granted to the journal.

This is an open-access article distributed under the terms and conditions of the Creative Commons Attribution license which permits unrestricted use, distribution, and reproduction in any medium, provided the original work is properly cited. 